\title{
A high-efficiency and low-operating-voltage green electrophosphorescent device employing a pure-hydrocarbon host material $\dagger$
}

\author{
Liang-Chen Chi, ${ }^{a}$ Wen-Yi Hung, ${ }^{* b}$ Hao-Chih Chiu ${ }^{b}$ and Ken-Tsung Wong* ${ }^{a}$ \\ Received (in Cambridge, UK) 12th March 2009, Accepted 24th April 2009 \\ First published as an Advance Article on the web 26th May 2009 \\ DOI: $10.1039 / b 904795 f$
}

A suitable triplet energy level and high morphological stability and hole mobility make indenofluorene an effective host material for green phosphorescent OLEDs.

The development of phosphorescent organic light-emitting devices (PhOLEDs) has attracted a great deal of attention because the incorporation of heavy metal-containing complexes into appropriate host materials can allow the harvesting of both singlet and triplet excitons, making it possible to render devices with close to $100 \%$ internal quantum efficiency. ${ }^{1}$ To obtain high quantum efficiency in a PhOLED, the host materials should possess (i) triplet energies higher than those of the guest molecules (to prevent exothermic reverse energy transfer), ${ }^{2}$ (ii) good charge balance properties (to effectively confine triplet excitons within the emitting layer), and (iii) good charge carrier transport properties (to achieve a low operating voltage). In this regard, Adachi et $a l .^{3}$ demonstrated efficient green PhOLEDs exhibiting external quantum efficiencies $\left(\eta_{\text {ext }}\right)$ close to $20 \%$ and power efficiencies $\left(\eta_{\mathrm{p}}\right)$ of $60 \mathrm{~lm} \mathrm{~W}^{-1}$ at low current densities $(<2 \mu \mathrm{A}$ $\mathrm{cm}^{-2}$ ) and low brightness. The values of $\eta_{\mathrm{ext}}$ and $\eta_{\mathrm{p}}$ for these devices decreased significantly, however, upon increasing the current, due to triplet-triplet annihilation of the phosphors; ${ }^{4}$ indeed, it is generally difficult to obtain high quantum efficiencies at high currents. Recently, much higher efficiencies have been obtained for modified PhOLED structures, such as those featuring hole- and exciton-blocking layers to confine holes and excitons within the emitting layer; ${ }^{5}$ nevertheless, the voltage drop across these layers requires more power to drive the devices, leading to high operating voltages and lower power efficiencies. This problem can be solved by increasing the conductivity of the organic layers, e.g., through doping with donors and acceptors that can significantly reduce the voltage drop across these films. By introducing a $p-i-n$ structure into an OLED, Pfeiffer $e t$ al. demonstrated highly efficient green-emitting PhOLEDs using the hole transport material TCTA as a host, obtaining high power efficiencies of $52 \mathrm{~lm} \mathrm{~W}^{-1}\left(\eta_{\mathrm{ext}}=c a .13 .7 \%\right)$ with $100 \mathrm{~cd} \mathrm{~m}^{-2}$ at $2.75 \mathrm{~V}$ and $45 \mathrm{~lm} \mathrm{~W}^{-1}\left(\eta_{\mathrm{ext}}=c a .12 .6 \%\right)$ with $1000 \mathrm{~cd} \mathrm{~m}^{-2}$ at $3.1 \mathrm{~V}^{6}$ Subsequently, they obtained a power efficiency of $77 \mathrm{~lm} \mathrm{~W}^{-1}$

${ }^{a}$ Department of Chemistry, National Taiwan University, Taipei 106, Taiwan.E-mail: kenwong@ntu.edu.tw; Fax:886 2 33661667; Tel: +886233661665

${ }^{b}$ Institute of Optoelectronic Sciences, National Taiwan Ocean University, Keelung 202. E-mail: wenhung@mail.ntou.edu.tw;

Fax: 8862 24634360; Tel: +886224622192 ext. 6718

$\dagger$ Electronic Supplementary Information (ESI) available: Synthetic procedure and spectroscopic characterizations, TGA, DSC, CV, and TOF hole mobility measurements. See DOI: 10.1039/b904795f/

and a value of $\eta_{\text {ext }}$ of $19 \%$ at $100 \mathrm{~cd} \mathrm{~m}^{-2}(2.75 \mathrm{~V})$ after $p$-doping the hole transporting layer (HTL), $n$-doping the electron transporting layer (ETL) and employing a double emission layer. ${ }^{7}$ Using a similar strategy, the Kido group recently reported ultrahigh-efficiency green PhOLEDs using $\operatorname{Ir}(\mathrm{ppy})_{3}$ as an emitter, realizing high values of $\eta_{\mathrm{p}}$ and $\eta_{\mathrm{ext}}$ (133 $\mathrm{lm} \mathrm{W} \mathrm{m}^{-1}$ and $29 \%$ at $100 \mathrm{~cd} \mathrm{~m}^{-2}$, respectively). ${ }^{8}$ As this approach increases the complexity of the device structure, the required fabrication processes would add considerably to the overall cost for mass production. Therefore, the challenge remains to develop new host materials to reduce the driving voltage while maintaining high quantum efficiencies at high luminance without the need for $p-i-n$-type OLED structures.

Several materials have been reported as hosts for highly efficient green electrophosphorescent devices, including $4,4^{\prime}, 4^{\prime \prime}$-tris $(N$-carbazolyl)triphenylamine (TCTA), 4,4'-bis(9-carbazolyl)biphenyl (CBP), 2,9-dimethyl-4,7-diphenylphenanthroline (BCP), 1,3-bis( N,N-tert-butylphenyl)-1,3, 4-oxadiazole (OXD7), and 3-phenyl-4-(1'-naphthyl)-5-phenyl1,2,4-triazole (TAZ). ${ }^{9}$ In a previous study, we employed spiroconfigured bi(9,9-diaryfluorene)s (triplet energy: $E_{\mathrm{T} 1}=2.3 \mathrm{eV}$ ) as effective host materials in green and red PhOLEDs. ${ }^{10}$ To better match the triplet energy of the green complexes, the conjugation length of the host must be selected carefully to achieve a wide energy gap and a high value of $E_{\mathrm{T} 1}$. Electron delocalization in $p$-phenylene linkages is extended along the elongated molecular axis, with $E_{\mathrm{T} 1}$ decreasing with the number of phenylene rings. The Yagi group reported that $p$-terphenyl has a value of $E_{\mathrm{T} 1}$ of $2.55 \mathrm{eV}$, making it suitable for use as a host for a green phosphorescent dopant. ${ }^{11}$ In this paper, we report a unique amorphous host material, SInF3, featuring a coplanar pure-hydrocarbon $p$-terphenylene (indenofluorene) backbone and exhibiting a high triplet energy, excellent thermal stability, and high hole mobility, making it suitable for use in green PhOLEDs. A device incorporating SInF3 as the host, accommodating bis(2-phenylpyridinato- $\left.N, C^{2 \prime}\right)$ iridium(acetylacetonate) ppy $_{2} \operatorname{Ir}(\mathrm{acac})^{12}$ as the green emitter, achieved a value of $\eta_{\mathrm{ext}}$ of $15.8 \%\left(60 \mathrm{~cd} \mathrm{~A}^{-1}\right)$ and a value of $\eta_{\mathrm{p}}$ of $63 \mathrm{~lm} \mathrm{~W}^{-1}$ at a practical brightness of $50 \mathrm{~cd} \mathrm{~m}^{-2}$ at $3 \mathrm{~V}$. Furthermore, the device provided a brightness of $10000 \mathrm{~cd} \mathrm{~m}^{-2}$ at an extremely low operating voltage $(5 \mathrm{~V})$; the efficiencies remained at $14 \%$ $\left(53.5 \mathrm{~cd} \mathrm{~A}^{-1}\right)$ and $33.6 \mathrm{~lm} \mathrm{~W}^{-1}$ - the highest values ever reported for green PhOLEDs lacking a $p-i-n$ junction. To the best of our knowledge, this is the first report of an indenofluorene derivative being used as an efficient host material for PhOLEDs. Scheme 1 displays our synthetic route toward SInF3. Suzuki coupling of the spirobifluorene-based boronic ester $\mathbf{1}$ and 2-iodoethyl benzoate gave the ester $\mathbf{2}$ in $92 \%$ yield. Double nucleophilic addition of $p$-tolyllithium 


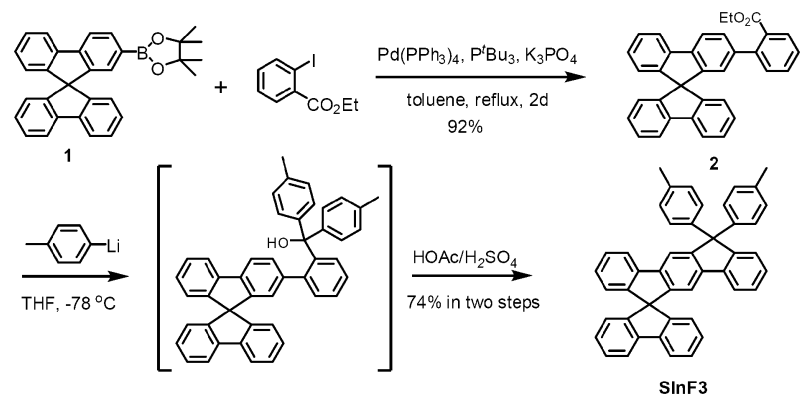

Scheme 1 Synthetic route toward SInF3.

onto the ester group of $\mathbf{2}$ and subsequent intramolecular Friedel-Crafts cyclization gave SInF3 in an isolated yield of $74 \%$.

We selected indenofluorene as the core structure of our green host because its derivatives possess rigid coplanar structures that enhance the conjugation, carrier mobility, and fluorescence quantum efficiency of the blue emission. ${ }^{13}$ The molecular design in SInF3 preserves the conjugated $p$-terphenyl backbone, which plays a prominent role in determining the overall electronic, electrochemical, and photophysical properties. The spiro configuration ${ }^{14}$ and peripheral $p$-tolyl substituent groups desymmetrize the molecule, thereby improving its thermal and morphological stability. SInF3 exhibits a high thermal tolerance [5\% weight loss occurred at $354{ }^{\circ} \mathrm{C}$, determined using thermogravimetric analysis (TGA)] and a distinct glass transition temperature $\left(T_{\mathrm{g}}\right)$ of ca. $171{ }^{\circ} \mathrm{C}$ [determined using differential scanning calorimetry (DSC)] (ESI, $\dagger$ Fig. S1). We observed completely different morphological behavior for SInF3 relative to that of its symmetric unsubstituted ${ }^{15}$ and tert-butyl-substituted ${ }^{16}$ dispirofluorene-indenofluorene (DSF-IF) derivatives, which are highly crystalline.

The small Stokes shift $(5 \mathrm{~nm})$ and the mirror image of the absorption and fluorescence spectra of SInF3 in $\mathrm{CHCl}_{3}$ (Fig. 1) confirm its molecular coplanarity and rigidity. The value of $E_{\mathrm{T} 1}$ of SInF3, which we estimated from the phosphorescence peak $(492 \mathrm{~nm})$ at $77 \mathrm{~K}$, was $2.52 \mathrm{eV}$; this value is close to that of the parent $p$-terphenylene $\left(E_{\mathrm{T} 1}=2.55 \mathrm{eV}\right)$ and higher than that of the green phosphorescent dopant $\operatorname{ppy}_{2} \operatorname{Ir}(\mathrm{acac})\left(E_{\mathrm{T} 1}=2.41 \mathrm{eV}\right)$. We used cyclic voltammetry to investigate the electrochemical properties of SInF3, observing one reversible oxidation process at $1.5 \mathrm{eV}(v s . \mathrm{Ag} / \mathrm{AgCl})$ $($ ESI, $\dagger$ Fig. S2). From the redox potential referenced to the

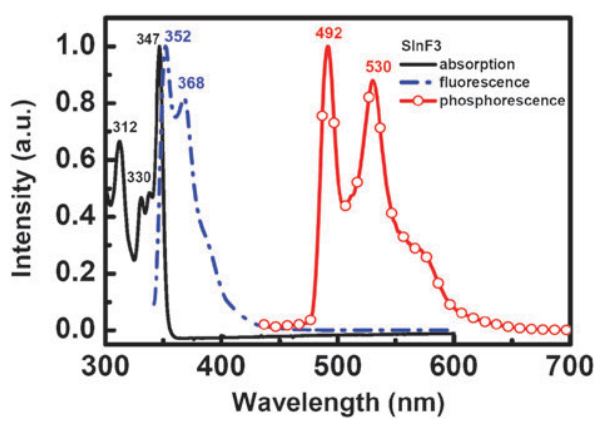

Fig. 1 Normalized UV-Vis absorption and fluorescence spectra $\left(\mathrm{CHCl}_{3}\right.$, room temperature) and phosphorescence spectrum $(\mathrm{EtOH}$, $77 \mathrm{~K})$ for SInF3. redox couple of ferrocene, we calculated the energy level of the highest occupied molecular orbital (HOMO) to be $-5.83 \mathrm{eV}$. Subtracting the optical band gap $(3.49 \mathrm{eV}$, determined from the cutoff of the optical absorption spectrum) from the HOMO energy level, we estimated the energy level of the lowest unoccupied molecular orbital (LUMO) to be $-2.34 \mathrm{eV}$. From the energy alignments, we anticipated efficient exothermic energy transfer from the SInF3 triplet state to the $\mathrm{ppy}_{2} \operatorname{Ir}(\mathrm{acac})$ triplet state, with excellent triplet energy confinement on the $\mathrm{ppy}_{2} \operatorname{Ir}(\mathrm{acac})$ molecules.

We performed a time-of-flight (TOF) measurement to evaluate the carrier mobility of SInF3. The TOF transient displays non-dispersive hole-transport characteristics, implying that the carriers moved with constant velocity across the SInF3 film (ESI, $\uparrow$ Fig. S3). In the double-logarithmic representation (inset to Fig. $\mathrm{S} 3 \dagger$ ), the transit time $\left(t_{\mathrm{T}}\right)$ can be determined from the intersection point of the two asymptotes. The hole mobilities of SInF3 as a function of the electric field (ESI, $\dagger$ Fig. S4) ranged from $3.9 \times 10^{-3}$ to $5.6 \times 10^{-3} \mathrm{~cm}^{2} \mathrm{~V}^{-1} \mathrm{~s}^{-1}$ for fields varying from $6 \times 10^{4}$ to $4.8 \times 10^{5} \mathrm{~V} \mathrm{~cm}^{-1}$, respectively. We attribute the high hole mobility of SInF3 to the spiro configuration (orthogonal arrangement) of its indenofluorene and peripheral fluorene units, which bridge and enhance the intermolecular charge transport of holes. ${ }^{17}$

Employing SInF3 as a host material, we fabricated a multilayer device having the configuration ITO/PEDOT-PSS $(30 \mathrm{~nm}) / \mathrm{NPB}(15 \mathrm{~nm}) /$ TCTA $(5 \mathrm{~nm}) / 10 \mathrm{wt} \% \mathrm{ppy}_{2} \operatorname{Ir}(\mathrm{acac})-$ doped SInF3 $(25 \mathrm{~nm}) / \mathrm{TPBI}(50 \mathrm{~nm}) / \mathrm{LiF}(0.5 \mathrm{~nm}) / \mathrm{Al}(100 \mathrm{~nm})$. In this device, PEDOT-PSS functioned as the hole injection layer; 4,4'-bis[ $N$-(1-naphthyl)- $N$-phenylamino]biphenyl (NPB) was the hole transport layer. To decrease the hole-injection barrier between NPB and the emitting layer, we incorporated a layer of $4,4^{\prime}, 4^{\prime \prime}$-tris $(N$-carbazolyl)triphenylamine (TCTA) because of its appropriately matching HOMO energy level. 1,3,5-Tris $(N$-phenylbenzimidizol-2-yl)benzene (TPBI) functioned as both the hole-blocking and ETL. Lithium fluoride $(\mathrm{LiF})$ was used as the electron-injection layer; aluminium (Al) was the cathode.

Fig. 2(a) presents the current density-voltage-luminance $(I-V-L)$ characteristics of this device. The $I-V$ and $L-V$ curves both feature steep increases after the turn-on voltage reached $2.5 \mathrm{~V}$. The operating voltage for a luminance of $1000 \mathrm{~cd} \mathrm{~m}^{-2}$ was $3.7 \mathrm{~V}$; a luminance of $10000 \mathrm{~cd} \mathrm{~m}^{-2}$ was achieved at voltages as low as $5 \mathrm{~V}$. The device exhibited an unusually high current of $c a .2700 \mathrm{~mA} \mathrm{~cm}$ ch $^{-2}$ at $9.5 \mathrm{~V}$, giving a maximum brightness of $255000 \mathrm{~cd} \mathrm{~m}^{-2}$. The electroluminescence (EL) spectrum [inset to Fig. 2(a)] reveals that the emission [CIE coordinates: $(0.32,0.64)]$ arose purely from $\mathrm{ppy}_{2} \operatorname{Ir}(\mathrm{acac})$, i.e., no emission occurred from the neighboring materials. Fig. 2(b) presents the values of $\eta_{\mathrm{ext}}$ and $\eta_{\mathrm{p}}$ as functions of the luminance. The maximum values of $\eta_{\text {ext }}\left[15.8 \%\left(60 \mathrm{~cd} \mathrm{~A} \mathrm{~A}^{-1}\right)\right]$ and $\eta_{\mathrm{p}}$ $\left(63 \mathrm{~lm} \mathrm{~W}^{-1}\right)$ were achieved at a practical brightness of $50 \mathrm{~cd} \mathrm{~m}^{-2}$ at $3 \mathrm{~V}$. It is noteworthy that even when the luminance reached $10000 \mathrm{~cd} \mathrm{~m}^{-2}$ (injection current density: $18.7 \mathrm{~mA} \mathrm{~cm}^{-2}$ ), the value of $\eta_{\mathrm{ext}}$ remained at $14 \%\left(54 \mathrm{~cd} \mathrm{~A}^{-1}\right)$. These results clearly indicate that appropriately designed host materials enable PhOLEDs to function with extremely low operating voltages without the need for a $p-i-n$ junction. We observed only a limited roll-off in the values of $\eta_{\text {ext }}$, even when the 

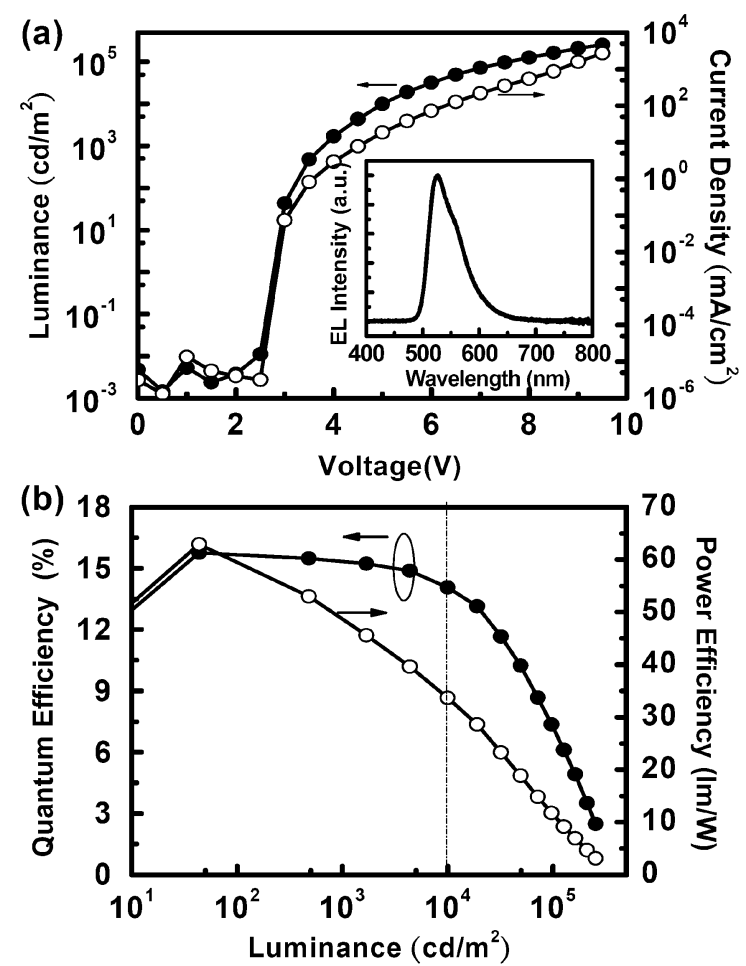

Fig. 2 (a) $L-V$ and $I-V$ characteristics. Inset: EL spectrum of the device. (b) Quantum efficiency-luminance and power efficiencyluminance characteristics.

luminance reached a value as high as $10000 \mathrm{~cd} \mathrm{~m}^{-2}$. We attribute the excellent performance of this device to the balanced injection of electrons and holes, and to the efficient confinement of triplet excitons generated within the emitting layer.

In conclusion, we have synthesized a pure-hydrocarbon host material, comprising a coplanar and rigid indenofluorene backbone presenting different peripheral aryl substituents, for use in green PhOLEDs. A device incorporating this tailor-made host material exhibited a brightness of $10000 \mathrm{~cd} \mathrm{~m}^{-2}$ at an extremely low operating voltage $(5 \mathrm{~V})$, with efficiencies of $14 \%\left(53.5 \mathrm{~cd} \mathrm{~A}^{-1}\right)$ and $33.6 \mathrm{~lm} \mathrm{~W}^{-1}$. Thus, PhOLEDs exhibiting high quantum efficiencies and low operating voltages at high brightness can be prepared without using complicated $p-i-n$ junction techniques.

\section{Notes and references}

1 M. A. Baldo, D. F. O’Brien, Y. You, A. Shoustikov, S. Sibley, M. E. Thompson and S. R. Forrest, Nature, 1998, 395, 151; C. Adachi, M. A. Baldo, S. R. Forrest and M. E. Thompson, Appl. Phys. Lett., 2000, 77, 904; Y. Kawamura, K. Goushi,
J. Brooks, J. J. Brown, H. Sasabe and C. Adachi, Appl. Phys. Lett., 2005, 86, 071104.

2 C. Adachi, R. C. Kwong, P. Djurovich, V. Adamovich, M. A. Baldo, M. E. Thompson and S. R. Forrest, Appl. Phys. Lett., 2001, 79, 2082; R. J. Holmes, S. R. Forrest, Y.-J. Tung, R. C. Kwong, J. J. Brown, S. Garon and M. E. Thompson, Appl. Phys. Lett., 2003, 82, 2422; S. Tokito, T. Iijima, Y. Suzuri, H. Kita, T. Tsuzuki and F. Sato, Appl. Phys. Lett., 2003, 83, 569; K. Goushi, R. Kwong, J. J. Brown, H. Sasabe and C. Adachi, J. Appl. Phys., 2004, 95, 7798.

3 C. Adachi, M. A. Baldo, M. E. Thompson and S. R. Forrest, J. Appl. Phys., 2001, 90, 5048.

4 M. A. Baldo, C. Adachi and S. R. Forrest, Phys. Rev. B, 2000, 62, 10967.

5 M. Ikai, S. Tokito, Y. Sakamoto, T. Suzuki and Y. Taga, Appl. Phys. Lett., 2001, 79, 156; V. Adamovich, S. R. Cordero, P. I. Djurovich, A. Tamayo, M. E. Thompson, B. Andrade and S. R. Forrest, Org. Electron., 2003, 4, 77; S. H. Kim, J. Jang and J. Y. Lee, Appl. Phys. Lett., 2007, 90, 223505; S.-O. Jeon, K. S. Yook, C. W. Joo, J. Y. Lee, K.-Y. Ko, J.-Y. Park and Y. G. Baek, Appl. Phys. Lett., 2007, 93, 063306.

6 M. Pfeiffer, S. R. Forrest, K. Leo and M. E. Thompson, Adv. Mater., 2002, 14, 1633; G. He, O. Schneider, D. Qin, X. Zhou, M. Pfeiffer and K. Leo, J. Appl. Phys., 2004, 95, 5773.

7 G. He, M. Pfeiffer, K. Leo, M. Hofmann, J. Birnstock, R. Pudzich and J. Salbeck, Appl. Phys. Lett., 2004, 85, 3911.

8 D. Tanaka, H. Sasabe, Y.-J. Li, S.-J. Su, T. Takeda and J. Kido, Jpn. J. Appl. Phys., 2007, 46, L10; D. Tanaka, N. Ide and J. Kido, Jpn. J. Appl. Phys., 2007, 46, 1186; H. Sasabe, T. Chiba, S.-J. Su, Y.-J. Pu, K. Nakayama and J. Kido, Chem. Commun., 2008, 5821.

9 C. Adachi, M. A. Baldo, S. R. Forrest and M. E. Thompson, Appl. Phys. Lett., 2001, 77, 904; H. Inomata, K. Goushi, T. Masuko, T. Konno, T. Imai, H. Sasabe, J. J. Brown and C. Adachi, Chem. Mater., 2004, 16, 1285.

10 K. T. Wong, Y. L. Liao, Y. T. Lin, H. C. Su and C. C. Wu, Org. Lett., 2005, 7, 5131.

11 J. Higuchi, K. Hayashi, M. Yagi and H. Kondo, J. Phys. Chem. A, 2002, 106, 8609; J. Higuchi, K. Hayashi, K. Seki, M. Yagi, K. Ishizu, M. Kohno, E. Ibuki and K. Tajima, J. Phys. Chem. A, 2001, 105, 6084 .

12 S. Lamansky, P. Djurovich, D. Murphy, F. Abdel-Razzaq, H.-E. Lee, C. Adachi, P. E. Burrows, S. R. Forrest and M. E. Thompson, J. Am. Chem. Soc., 2001, 123, 4304.

13 D. Horhant, J.-J. Liang, M. Virboul, C. Poriel, G. Alcaraz and J. Rault-Berthelot, Org. Lett., 2006, 8, 257; Y. Wu, J. Zhang and Z. Bo, Org. Lett., 2007, 9, 4435; D. Vak, B. Lim, S.-H. Lee and D.-Y. Kim, Org. Lett., 2005, 7, 4229; T. Hadizad, J. Zhang, Z. Y. Wang, T. C. Gorjanc and C. Py, Org. Lett., 2005, 7, 795; K.-T. Wong, L.-C. Chi, S.-C. Huang, Y.-L. Liao, Y.-H. Liu and Y. Wang, Org. Lett., 2006, 8, 5029.

14 T. P. I. Saragi, T. Spehr, A. Siebert, T. Fuhrmann-Lieker and J. Salbeck, Chem. Rev., 2007, 107, 1011.

15 C. Poriel, J.-J. Liang, J. Rault-Berthelot, F. Barrie're, N. Cocherel, A. M. Z. Slawin, D. Horhant, M. Virboul, G. Alcaraz, N. Audebrand, L. Vignau, N. Huby, L. Hirsch and G. Wantz, Chem.-Eur. J., 2007, 13, 10055.

16 C. Poriel, J. Rault-Berthelot, F. Barrie're and A. M. Z. Slawin, Org. Lett., 2008, 10, 373.

17 C.-C. Wu, W.-G. Liu, W.-Y. Hung, T.-L. Liu, Y.-T. Lin, H.-W. Lin, K.-T. Wong, Y.-Y. Chien, R.-T. Chen, T.-H. Hung, T.-C. Chao and Y.-M. Chen, Appl. Phys. Lett., 2005, 87, 052103. 